\title{
Hands on Experiments about Water Needs in Agriculture and Their Mathematical Modelling under Climate Change
}

\author{
Maria T. Malheiro \\ University of Minho \\ Department of Mathematics and \\ Mathematics Center, Braga, Portugal \\ +351253510440 \\ mtm@math.uminho.pt
}

\author{
Paulo A. S. Pereira \\ University of Minho \\ Department of Mathematics and \\ Mathematics Center, \\ Braga, Portugal \\ +351253510439 \\ ppereira@math.uminho.pt
}

\author{
Rui M. S. Pereira \\ University of Minho \\ Department of Mathematics and \\ Physics Center, Braga, Portugal \\ +351253510436 \\ rmp@math.uminho.pt
}

\author{
A. Manuela Gonçalves \\ University of Minho \\ Department of Mathematics and \\ Mathematics Center, Braga, Portugal \\ +351253510433 \\ mneves@math.uminho.pt
}

\author{
Amélia C. Caldeira \\ Department of Mathematics, School of \\ Engineering, Polytechnic of Porto. \\ LEMA|ISEP and SYSTEC|ISR \\ Portugal \\ +351228 340500 \\ acd@isep.ipp.pt
}

\author{
Sofia O. Lopes \\ University of Minho \\ Department of Mathematics and \\ Physics Center, Braga, \\ SYSTEC|ISR, Portugal \\ +351253510441 \\ sofialopes@math.uminho.pt
}

\begin{abstract}
In this paper, we intend to present the planning of experiences that can be presented to students of school age. These experiments have the goal of sensitizing students to climate changes, the problem of water scarcity and the need to save it. At the same time, the experiences give an opportunity to show through concrete cases how Mathematics can model natural phenomena in order to understand them better and predict future behavior. Agriculture is the economic sector that spends more water with low degree of efficiency (about $60 \%$ ). Efficient irrigation systems are necessary, and smart irrigation systems are being designed and implemented in our research group, https://sofialope6.wixsite.com/to-chair. In order to achieve smart irrigation, complex mathematical models were developed and programmed in MatLab/Octave. However, purpose of this paper is to motivate students to this issue. In particular, we intend to show how mathematics can be a fun, and valuable tool to understand many concepts linked with smart irrigation. We describe a set of simple experiments, that can easily be performed at home, that may be a valuable tool to understand "hands on" concepts like soil differences, evapotranspiration, soil moisture and infiltration of water in the soil and efficiency of the water used.
\end{abstract}

\section{CCS Concepts}

- Applied computing $\rightarrow$ Interactive learning environments • Mathematics of computing $\rightarrow$ Probability and statistics.

\footnotetext{
Permission to make digital or hard copies of all or part of this work for personal or classroom use is granted without fee provided that copies are not made or distributed for profit or commercial advantage and that copies bear this notice and the full citation on the first page. To copy otherwise, or republish, to post on servers or to redistribute to lists, requires prior specific permission and/or a fee. Request permissions from Permissions@acm.org.

ICSET 2019, August 15-17, 2019, Taipei, Taiwan.

(C) 2019 Association for Computing Machinery.

ACM ISBN 978-1-4503-7230-5/19/08_..\$15.00

DOI: https://doi.org/10.1145/3355966.3358411
}

\section{Keywords}

Climate change; agriculture, smart irrigation; mathematics education.

\section{INTRODUCTION}

Climate change is a current subject, with large discussions and facts present in all media and social networks. Consequences of climate change came sooner than expected strongly affecting our planet and all living things that inhabit it, [1], [2]. Human activities are responsible for climate change. Therefore, it is urgent to change those human actions that negatively influence the climate. Education plays a key role here. Sensitizing school age youth to the problem and the need to change attitudes and actions is extremely relevant, not only because of the change that may occur in young people, but also because of the influence they have on their parents, peers and future generations. One of our time's demands is the efficient use of natural resources that have always seemed inexhaustible, but that really are not. In the future, drinking water will be a scarce commodity and we must now make efficient use of this indispensable resource for life. Agriculture is the economic sector that spends more water with low efficiency (about 60\%). Water is indispensable for life and growth of cultures. One of the consequences of climate variations is the gradual loss of soil productivity and vegetation and this will be visible, with a marked intensity, in Southern Europe. The water needs that typically occur every year in the spring and summer periods strongly affects the agriculture production. However, use of water for irrigation is not efficient. For this to be possible, it is necessary to consider the type of crop and its water needs, the type of soil where it is grown and the region climate. It is here that Mathematics and Optimization in particular play their fundamental role. Using mathematical language, we can model phenomena, represent their functioning, and predict behaviors. The importance of the study of irrigation systems can be seen in [3]. This paper's authors have been developing mathematical models that intend to optimize irrigation planning, [4]-[10]. Smart irrigation systems are being designed and implemented in our 
research group (see https://sofialope6.wixsite.com/to-chair). In order to achieve smart irrigation, complex mathematical models were developed and programmed in MatLab/Octave.

With this work, we intend, via technology, to combine mathematical modeling and technology with the students' awareness of climate change, through an everyday life problem. The last international PISA test was developed by the OECD to evaluate the literacy of 15-yearolds from around the world in Reading, Mathematics and Science, thus contributing to the collection of information on the performance and characteristics of educational systems of various countries and economies. Only one EU country managed to reach the 10th place in mathematics and only two countries have been amongst the Top10 in science. Portugal reached the following positions: 17th to Sciences with 501 points, 18th in Reading with 498 points and 22th to Mathematics with 492 points (considering only the 35 countries / economies that make up the OECD, of the 72 participants in the study). PISA has revealed a great disadvantage in problem solving and modelling. European pupils have not been able to cope with everyday life problems. Knowing in addition that there is a strong correlation between math knowledge and later career, there is also a correlation between social status and math skills. Therefore, there is a strong need to strengthen European pupils in mathematics. The teachers, for many years, were trained to teach in the same way that they were taught. However, the advances in technology are rapidly changing the way that students learn, both in school and beyond it. As technology has rooted its way into our day-to-day existence, education has been changed. With information at the tips of our fingers, learning is now boundless.

It is in this background that activities described here are contextualized. We planned experiments easy for students and possible to adapt for different levels of schooling. Their objectives are:

- To "wake up" young people to the efficient use of water scarce but essential to life;

- To show the need to analyze different aspects of the problem of crop irrigation: type of crop, type of soil, stage of crop life, evapotranspiration phenomenon, climatic conditions...;

- To show how Mathematics can help to solve practical problems, modeling, representing and predicting behavior of phenomena;

- Show how, in this specific problem, we can use mathematical tools.

Thus, we present experiments that are easy to perform. We need several pots with different soil types, some without and others with different plants, a humidity sensor and an Excel sheet.

Students can perform experiments, collect soil moisture data on an Excel sheet, and obtain a mathematical expression that models the behavior of the data. Depending on the school age, the activities can be adapted:

- 1st cycle students can experiment and collect data on an Excel sheet, gaining sensitivity for instrument reading, for non-integer numbers and relation of order in non-integer numbers.

- 2nd and 3rd cycle students can experiment and collect data in an Excel sheet and use Excel's own tools to get the curve and its mathematical expression (a polynomial) that best models the data.
- Secondary students may, in addition to the activities described in the previous point, understand how the curve was obtained using Regression Analysis from Statistics.

\section{MAIN CONCEPTS IN IRRIGATION}

In this section, an "easy to understand" explanation of the main variables to take into account, to design a good irrigation system is presented. Technical details are not given, since it has to be simple enough for a first cycle student to grasp the concept. Figure 1 illustrates the cycle of water in a farm field and presents the main involved concepts.

Water Efficiency and Irrigation: In agriculture, water efficiency is reducing water wastage by measuring the amount of water required for a healthy crop and the amount of water used or delivered - is the $\%$ of the used water useful for the crop. It is one of the main challenges we face - it is crucial to save water, especially in agriculture, see [11], [12]. Most irrigation systems (when they exist) are of type on - off, [3]. They don't care if the soil has already enough water or not. This can be tackled using a smart irrigation system like the one designed by our team.

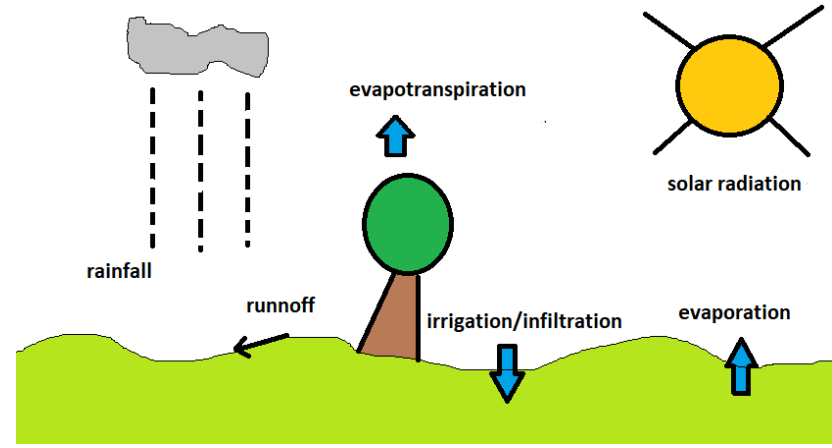

Figure 1. The main cycle of water in a farm field.

Types of soils: In a crop field, we may have different types of soils. The main types are sandy soil, clay soil, silt soil, peat soil, chalk soil and loam soil, see Figure 2. This will strongly affect how fast the water infiltrates the soil and how much water can the soil retain for a given time if there is a long drought. The type of soil should be an important issue to take into account by the decision makers when deciding the crops to cultivate. Next, we explain in simple words some of the main variables to take into account to be able to design a proper irrigation system.

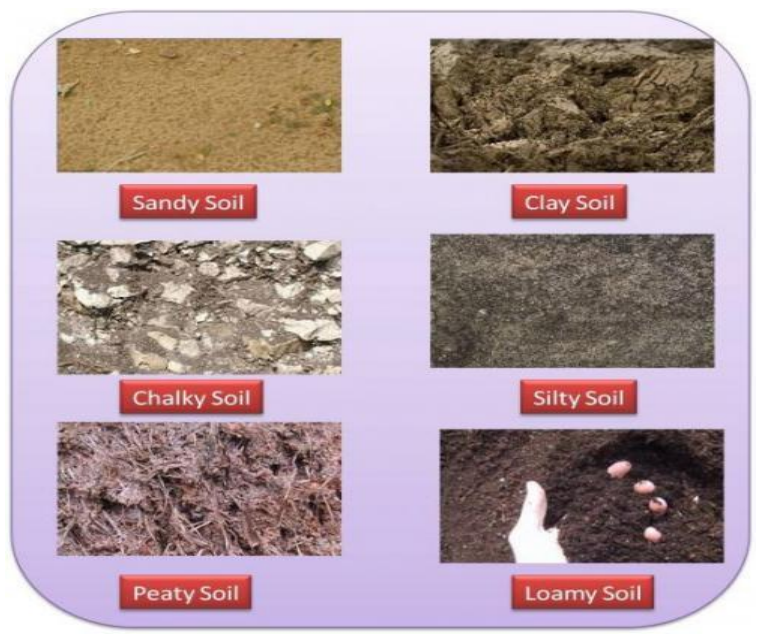

Figure 2. Different types of soil.

In https://www.tutorvista.com/biology/picturesof-types-of-soil. 
Evapotranspiration: If a plant exists in a crop field, it produces evapotranspiration. Includes water needed to live, grow and reproduce. Each type of plant has a different amount of evapotranspiration, and even the same plant has different levels depending on the weather conditions and its phase growth.

Weather variables: The type of weather in the region will strongly affect the crops growth. Solar radiation, wind speed, temperature, and rainfall, are very important to understand if the type of crops are ideal in a certain site. However, climate change is affecting drastically these variables over time. Mathematical models involving time series and others, help create different scenarios over the future years. Note that these variables are crucial to estimate the evapotranspiration, see [13], [14].

\section{HANDS ON EXPERIMENTS TO STUDY SOME IRRIGATION PARAMETERS}

The first thing we need, is a moisture sensor. This can be bought in any store that as a section dedicated to gardening. You may get such a gadget for less than 20 euros, or a bit more if you want it to be more accurate. The set of experiments we describe are easy to perform. You only need this moisture sensor, different soils, water, one or more plants and a wristwatch. Then you collect the data and use a spreadsheet like Excel. We tried this in the garden of one of the authors. After choosing the right spot without surrounding plants, you place the moisture sensor on the soil and measure the initial value. Afterwards we irrigated the vicinity of the sensor ( 0.45 liters of water), and collected the moisture sensor level every minute, for about 8 minutes, when moisture tended to be stable. (Table 1)

Table 1. Soil moisture function of time without crop. During $1^{\text {st }}$ minute $0.45 \mathrm{~L}$ of water irrigated in vicinity of the sensor.

\begin{tabular}{|c|c|}
\hline Time(m) & Moisture Level (0-4) \\
\hline 0 & 1.2 \\
\hline 1 & 1.7 \\
\hline 2 & 1.7 \\
\hline 3 & 1.65 \\
\hline 4 & 1.6 \\
\hline 5 & 1.55 \\
\hline 6 & 1.5 \\
\hline 7 & 1.5 \\
\hline 8 & 1.5 \\
\hline
\end{tabular}

The mathematical model used to represent reality was Regression Analysis. It is a form of predictive modeling technique which investigates the relationship between dependent (response) and independent variable (s) (predictor). This technique is used for modeling and forecasting, and finding the causal effect relationship between the variables. Regression Analysis is an important tool for modeling and analyzing data. In Regression Analysis, polynomial regression is a type of nonlinear models. A regression equation is a polynomial regression equation if the power of independent variable is more than 1 . Here, we fit a curve/line to the data points, in such a manner that the differences between the distances of data points from the curve or line is minimized. In this regression technique, the best fit line is not a straight line. It is rather a curve that fits into the data points, in our case,

$$
y(t)=\beta_{0}+\beta_{1} t+\beta_{2} t^{2}+\beta_{3} t^{3}+\beta_{4} t^{4}+\epsilon_{t}
$$

where the coefficients $\beta_{j}, j=1, \cdots, 4$ are determined to obtain the best fit, and $\epsilon_{t}$ is the so-called random error. It is useful to have some measure of how well the model fits the data. One common choice is R Square $\left(R^{2}\right)$, the so-called coefficient of determination or percentage of variance explained. Its range is $0 \leq R^{2} \leq$ with values closer to 1 indicating better fits. Excel multiple regression can be performed by adding a trend line, or by using the Excel Data Analysis Toolpak. If we just want to know the equation for the line of best fit, adding a trend line will work well.

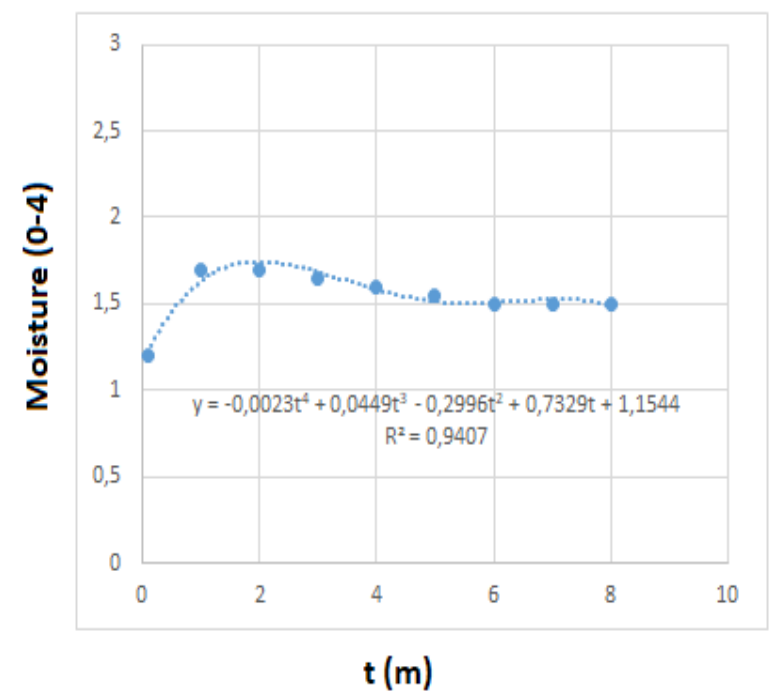

Figure 3. Soil Moisture function of time - spot without plant. Mathematical model explaining infiltration and $\boldsymbol{R}^{2}$ are added.

In this example, we may see that a 4 th degree polynomial seems to describe very well the experimental data, see Figure 3 . The students should note that other models could be chosen, and for instance if the soil or the amount of water used were different, results would be different. With this practical example, a student may understand the importance of mathematical models to mimic reality and also learn some statistical concepts in a funny way. Then, we chose a different soil. We considered Biological Substrate only. The experiment was repeated and the results were as follows. (Table 2)

Table 2. Soil moisture function of time without crop. Biological substrate is the soil. During $1^{\text {st }}$ minute $0.45 \mathrm{~L}$ of water irrigated in vicinity of the sensor.

\begin{tabular}{|c|c|}
\hline Time(m) & Moisture Level (0-4) \\
\hline 0 & 0.7 \\
\hline 1 & 2.7 \\
\hline 2 & 2.8 \\
\hline 3 & 2.8 \\
\hline 4 & 2.8 \\
\hline 5 & 2.8 \\
\hline 6 & 2.8 \\
\hline 7 & 2.8 \\
\hline 8 & 2.75 \\
\hline
\end{tabular}

The whole procedure described before is performed once more. 


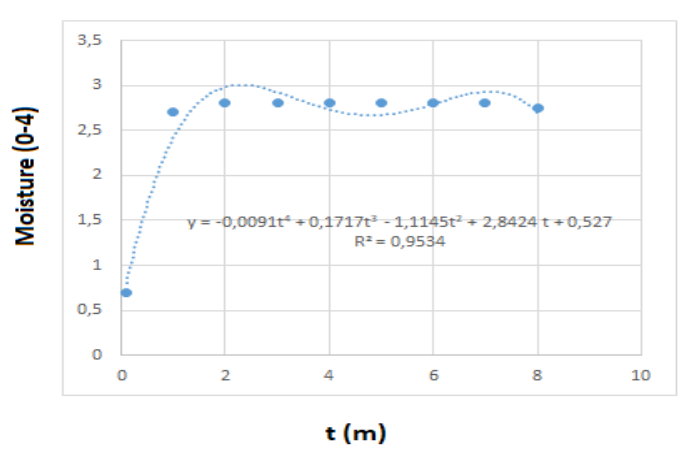

Figure 4. Soil Moisture function of time in a spot without plant now we use bio substrate as soil.

We obtain a very good fit with a 4th degree polynomial but with different coefficients as expected, see Figure 4. The curious thing here, is that after reaching the maximum soil moisture does not drop as fast as in the first experiment. This tells us that this biological substrate retains the water much better. Other soils could be tried but, he point was to give the students the notion that the type of soil can determine how well a plant can survive a draught period. Among many important issues, another experiment, may also be very useful. In the same garden (going back to the original type of soil), we now chose a spot with surrounding grass and plants. We repeated the experiment. The results are represented in the following Table 3. The whole procedure in Excel was repeated.

Table 3. Soil moisture function of time in a site of grass and other plants. Original soil used. During $1^{\text {st }}$ minute $0.45 \mathrm{~L}$ of water irrigated in vicinity of the sensor.

\begin{tabular}{|c|c|}
\hline Time(m) & Moisture Level (0-4) \\
\hline 0 & 1.7 \\
\hline 1 & 2.25 \\
\hline 2 & 2.25 \\
\hline 3 & 2.2 \\
\hline 4 & 2.2 \\
\hline 5 & 2.15 \\
\hline 6 & 2.1 \\
\hline 7 & 2.1 \\
\hline 8 & 2.1 \\
\hline
\end{tabular}

The whole procedure described before is performed once more.

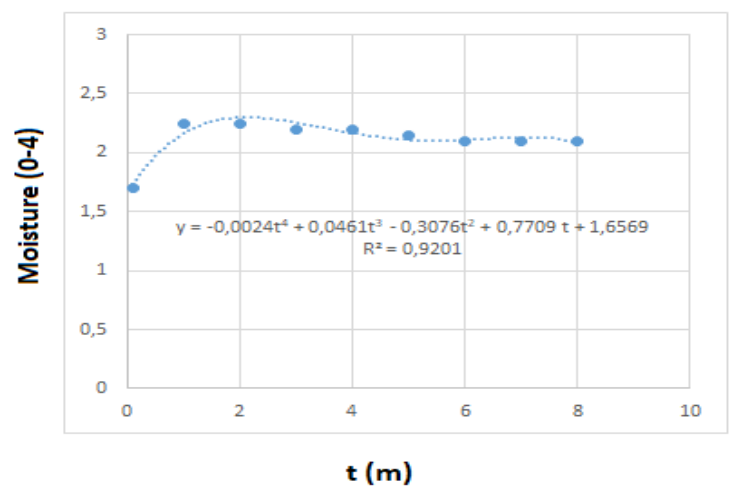

Figure 5. Soil Moisture function of time in a spot near grass and other plants, first soil again.
This third experiment was done a few meters away from the first one and a few minutes later. So, it is interesting to notice that before irrigating, the soil moisture was well above now. This means the existence of plants, on its own guarantees a higher moisture level of the soil. They retain water. The behavior of soil moisture is similar, (see Figure 5) yet the percentage of soil moisture dropping in the 8 minutes of the experiment is smaller than the first experiment. This confirms that plants are important to keep soil moisture. This is partly justified by evapotranspiration. If you have a plant in a certain place, evapotranspiration exists, meaning that in order to survive the plant will take water from the soil, and as all living beings also transpires. Evapotranspiration is composed of evaporation and plant transpiration to the atmosphere. To finish up the experiments, on a very hot day (25 Celsius), we now placed the moisture sensor near a Cactus plant. We then irrigated land in the vicinity of the Cactus with 0.45 liters of water. The results can be seen in the next Table 4 .

Table 4. Soil moisture function of in site near a cactus.

Original soil used, at noon of a hot day (25 Celsius). During $1^{\text {st }}$ minute $0.45 \mathrm{~L}$ of water irrigated in vicinity of the sensor.

\begin{tabular}{|c|c|}
\hline Time(m) & Moisture Level (0-4) \\
\hline 0 & 1.2 \\
\hline 1 & 1.4 \\
\hline 2 & 1.5 \\
\hline 3 & 1.5 \\
\hline 4 & 1.55 \\
\hline 5 & 1.55 \\
\hline 6 & 1.6 \\
\hline 7 & 1.65 \\
\hline 8 & 1.65 \\
\hline
\end{tabular}

The whole procedure described before is performed once more.

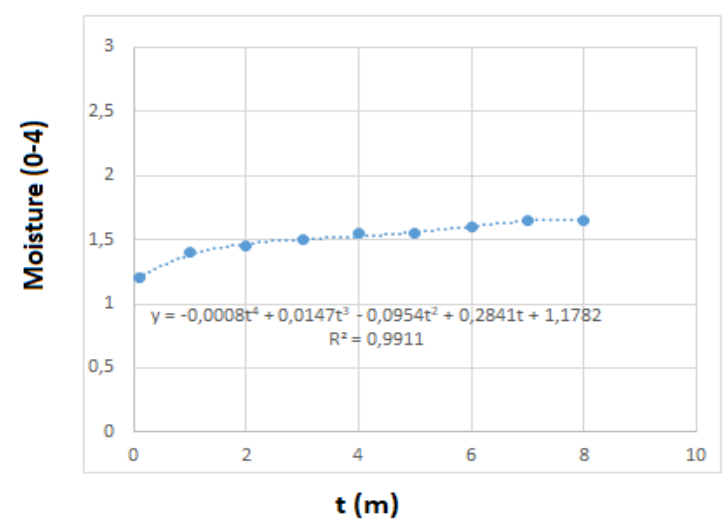

Figure 6. Soil Moisture function of time in a spot near a Cactus, first soil again, but at noon of a hot day (25 Celsius).

From the measurements, we can see that in 8 minutes, the soil moisture did not stop growing completely, see Figure 6. Unlike grass, the Cactus is able to retain water for longer time. In the case of grass after just 1 minute, soil moisture was already dropping. This is an expected result. They actually are able to live in the desert where rainfall very rarely happens. We were able to see that different crops retain water differently, as expected. 


\section{CONCLUSION}

The contents of this paper are twofold. First, we present the students a very real and urgent problem, that is Climate Change. We have to be educated to save the Earth's resources, recycle and be friends with Nature. Water is a crucial good we have to take care with the most urgency. To save water we need an efficient agriculture that is able to produce the most goods without spending too much water. Smart irrigation is needed. On the other hand to deal with smart irrigation, we need to understand some of the main variables that influence its efficiency. We planned some simple experiments that will motivate the students to understand some of the main aspects involved in a crop field. There are already known and good models to represent infiltration of water in the soil. We intended to make students aware to the Climate change and its consequences with a a very simple one, and at the same time try to apply some mathematics/statistics in a more interesting way. This is done via mathematical models, learned in statistics, allowing the learning process to be fun and rigorous at the same time. In this case, we introduced non-linear regression using data from an experience of water infiltration. Some more interesting results could be taken should the experiences could take longer but we know students tend to want results on "real time" and Nature does not use the same time frame. The experiment was short in its duration, to make the most of students' interest and concentration. We believe that learning mathematics and see its application on a hot issue like Climate Change may be a good way to go.

\section{ACKNOWLEDGMENT}

FEDER/COMPETE/NORTE2020/POCI/FCT funds through grants UID/EEA/00147/20 13/UID/IEEA/00147/ 006933SYSTEC, PTDCEEI-AUT-2933-2014116858TOCCATA, project, To CHAIR - POCI-01-0145-FEDER-028247 and UPWIND POCI -FEDER-FCT -31447. Financial support from the Portuguese Foundation for Science and Technology (FCT) in the framework of the Strategic Funding UID/FIS/04650/2019 and UID/MAT/00013/2013 is also acknowledged.

\section{REFERENCES}

[1] IPCC, Fourth assessement report on climate change 2007 Synthetis report - summary for policy makers, Intergovernmental Panel on Climate Change, (2007).

[2] Stocker, T.F.D., Qin, G-K., Plattner, M., Tignor, S.K., Allen, J., Boschung, A., Nauels, Y., Xia, V.B. and Midgley, P.M. 2013. IPCC, 2013: climate change 2013: the physical science basis", Contribution of Working Group I to the Fifth Assessment Report of the Intergovernmental Panel on Climate Change, Cambridge University Press, (2013). DOI: 10.1017/CBO9781107415324

[3] Valipour, M., Sefidkouhi, M. and Eslamian, S. 2015. Surface irrigation simulation models: a review, International Journal of Hydrology Science and Technology, 5(1), .51-70, (2015).
[4] S. Lopes, F. Fontes, R. M. S. Pereira, and G. J. Machado, 2012. Irrigation planning in the context of climate change, Mathematical Models for Engineering Science - MMES11, 239-244, (2011).

[5] S. Lopes, F. Fontes, R. M. S. Pereira, A.M. Gonçalves and G. J. Machado 2013. Irrigation Planning: an optimal control approach, International Conference of Numerical Analysis and Applied Mathematics, AIP Conference Proceedings, 1558, 622-626, (2013).

[6] Sofia O. Lopes, F. A.C.C. Fontes, Rui M.S. Pereira, MdR de Pinho and C. Ribeiro, 2015.Optimal Control for an Irrigation Planning Problem: Characterization of Solution and Validation of the Numerical Results, Lecture Notes in Electrical Engineering, 321, 157-167, (2015).

[7] Sofia O. Lopes, Rui M. S. Pereira, Fernando A. C. C. Fontes, MdR. Pinho and Gaspar J. Machado, 2014.Optimal Control of the Irrigation Problem: Characterization of the Solution, Procedia Technology, 17, 699-704, (2014).

[8] S.O. Lopes, F.A.C.C. Fontes, R.M.S. Pereira, MdR. de Pinho and A.M. Gonçalves, 2016. Optimal control applied to an irrigation planning problem, Mathematical Problems in Engineering, (2016).

[9] S.O. Lopes and F.A.C.C. Fontes, 2017. Optimal Control for an irrigation problem with several fields and a common reservoir, CONTROLO 2016, Springer, 179-188, (2017).

[10] S.O. Lopes, Rui M. S. Pereira, Amélia Caldeira and Victor Fonte, 2019. Optimal Control Applied to an Irrigation Planning Problem: a real case study in Portugal, International Journal of Hydrology Science and Tecnology, 9(2), (2019)

[11] Dalezios, R., Angelakis, A., Eslamian, S. 2018. Water scarcity management: Part 1: methodological framework, International Journal of Hydrology Science and Technology, 17(1), (2018).

[12] Haie, N., Pereira, R.M.S., Machado, G. and Keller, A. 2012. Analysis of effective efficiency in decision making for irrigation interventions, Water Resources, 39(6), 700-707, (2012).

[13] Allen, R., Pereira, L., Raes, B. and Smith, M. Crop Evapotranspiration (Guidelines for Computing Crop Water Requirements), FAO Irrigation and Drainage Paper (1998).

[14] Walter, I., Allen, R., Elliott, R., Itenfisu, D., Jensen, M., Mecham, B., Howell, T., Snyder, R., Brown, S., Echings, S., Spofford, T., Hattendorf, M., Cuenca, R., Wright, J. and Martini, D. 2016. The ASCE standardized reference evapotranspiration equation, Rep. Task Com. on Standardized Reference Evapotranspiration, (2016). 